\title{
Endogenous female sex hormones delay the development of renal dysfunction in apolipoprotein E-deficient mice
}

\author{
Sonila S Carneiro ${ }^{1}$, Raffaela Z Carminati ${ }^{1}$, Flavia PS Freitas ${ }^{1}$, Priscila L Podratz ${ }^{2}$, Camille M Balarini ${ }^{3}$,
} Jones B Graceli ${ }^{2,4,6^{*}}$, Silvana S Meyrelles ${ }^{1}$, Elisardo C Vasquez ${ }^{1,5}$ and Agata L Gava ${ }^{1 *}$

\begin{abstract}
Background: Hypercholesterolemia is a well-established risk factor for the development of kidney injury. Considering that female sex hormones may play a preventative role in both cardiovascular and renal diseases, the aim of the present study was to evaluate the effects of female sex hormones on hypercholesterolemia-induced renal dysfunction.

Methods: Apolipoprotein E-deficient (ApoE) and C57 control female mice underwent an ovariectomy (OVX) or sham surgery and after 2 months, creatinine clearance, uremia and proteinuria were determined. Renal oxidative stress and lipid deposition were also quantified. Values are presented as mean \pm SEM. Statistical analyses were performed using Two-way ANOVA followed by Tukey's post hoc test.

Results: Creatinine clearance ( $\mu \mathrm{L} / \mathrm{min})$ was similar between C57 (171 \pm 17$)$ and ApoE (140 \pm 26$)$ mice underwent sham surgery. OVX resulted in a reduced glomerular filtration rate in both $C 57(112 \pm 8, \sim-35 \%, p<0.05)$ and ApoE $(61 \pm 10, \sim-56 \%, p<0.05)$ animals. Plasma levels of urea $(\mathrm{mg} / \mathrm{dL})$ were higher in both ApoE groups (Sham: $73 \pm 7$; OVX: $73 \pm 8, p<0.05$ ) when compared to C57 animals (Sham: $49 \pm 3$; OVX: $60 \pm 4$ ), with no changes among ovariectomized groups. Proteinuria levels ( $\mathrm{mg} / 24 \mathrm{~h}$ ) were similar between C57 (Sham: $25.1 \pm 5.7 ;$ OVX: $33.7 \pm 4.7$ ) and ApoE sham animals ( $26.4 \pm 3.5)$, however, 24 -h urine protein excretion was augmented in ApoE OVX animals (49.6 \pm 5.8 , $p<0.05)$. Histological kidney analysis demonstrated that the absence of female sex hormones resulted in increased oxidative stress, which was more severe in ApoE mice (C57 Sham: 9.2 \pm 0.4; C57 OVX: $22.9 \pm 1.0$; ApoE Sham: $13.9 \pm 0.7$; ApoE OVX: $34.0 \pm 1.4$ au $\left.\times 10^{3}, p<0.05\right)$. As expected, ApoE mice presented higher lipid deposition, which was not affected by OVX (C57 Sham: $0 \pm$ 0; C57 OVX: $0 \pm$ 0; ApoE Sham: $6.8 \pm$ 1.6; ApoE OVX: $5.2 \pm 0.8 \% \times 10^{-2}, p<0.05$ ). Ovariectomy resulted in a similar reduction in ER-a protein expression in the renal cortex (C57: 0.78 \pm 0.04 ; ApoE: $0.81 \pm 0.04 \mathrm{au}, \mathrm{p}<0.05)$ when compared to sham animals (C57:1.00 $\pm 0.04 ;$ ApoE: $1.03 \pm 0.03 \mathrm{au}$ ).
\end{abstract}

Conclusion: Taken together these data indicate that female sex hormones may delay hypercholesterolemia-induced renal dysfunction and emphasizes the importance of plasma cholesterol control in post-menopausal women.

Keywords: Female sex hormones, Hypercholesterolemia, Renal function

\footnotetext{
* Correspondence: jbgraceli@gmail.com; agatagava@hotmail.com

${ }^{2}$ Morphology Department, Health Sciences Center, Federal University of Espirito Santo, Vitoria, ES, Brazil

${ }^{1}$ Laboratory of Translational Physiology, Physiological Sciences Graduate Program, Health Sciences Center, Federal University of Espirito Santo, Av Marechal Campos 1468, 29042-755 Vitoria, ES, Brazil

Full list of author information is available at the end of the article
} 


\section{Background}

Atherosclerosis is a complex disorder that leads to premature death and hospitalization [1]. Vascular lipid deposition and the resultant cardiovascular complications, such as myocardial infarction, stroke and ischemic heart failure, are the major cause of death in the Western world [2]. Although cardiovascular outcomes can be considered one of the most significant consequences of atherosclerosis, this disease can also contribute to the development and/or progression of renal diseases, such as chronic kidney disease (CKD) [3].

Experimentally, atherosclerosis can be induced by the inactivation of the apolipoprotein-E (apoE) gene by homologous recombination [4,5]. Among the genetically engineered models, the apoE-deficient $\left(\mathrm{apoE}^{-} /^{-}\right)$mouse is considered to be one of the most relevant models because it develops spontaneous hypercholesterolemia and arterial lesions similar to those observed in humans [6]. $\mathrm{ApoE}^{-/-}$mice present higher levels of plasma cholesterol when compared to wild-type animals. The lipid profile in mice differs from that in humans, who carry most of the serum cholesterol in LDL particles. Normally, mice do not express cholesterol-ester transfer protein (CETP) and thus carry most of their plasma cholesterol in HDL particles [7]. However apoE ${ }^{-/-}$mice lipid profile resembles that found in humans, once they present a shift in plasma lipoprotein from HDL to cholesterol-rich remnants of chylomicrons and VLDL [8].

The main risk factors associated with atherosclerosis are well known, including hypertension, diabetes, smoking and increased serum total and low-density lipoprotein cholesterol [2]. Among these, it is interesting to note that hypercholesterolemia is also considered a contributing factor towards the development of renal dysfunction [9]. In fact, the prevalence of dyslipidemia in patients with CKD is much greater than in the general population [10]. On the other hand, the progressive deterioration of renal function associated with CKD may also lead to dyslipidemia, which contributes to the development of atherosclerosis [11]. As such, dyslipidemia and atherosclerosis accelerate renal dysfunction, which in turn, promotes atherosclerosis.

Gender is a non-modifiable risk factor that influences the progression of atherosclerosis and renal diseases. The majority of studies show that during their reproductive years, women are less prone to developing cardiovascular disease and atherosclerosis, but men and post-menopausal women of comparable age are at equal risk [12]. Furthermore, population-based studies indicate that men present a more severe CKD progression than women $[13,14]$. Estrogens can mediate several beneficial effects on renal function, including suppression of extracellular matrix synthesis in the glomerular mesangial cells [15], reduced tubulointersticial fibrosis [16] and increased NO production and/or bioavailability $[17,18]$. Based on these data, the goal of the present study was to evaluate the protective role of endogenous female sex hormones on hypercholesterolemia-induced renal dysfunction in apoliprotein-E deficient mice, an experimental murine model of hypercholesterolemia and atherosclerosis. Our data demonstrate that the ovariectomy led to a significant loss of renal function in hypercholesterolemic mice.

\section{Results}

The results of body weight, dry uterus weight and the uterus atrophy index, given by the ratio between dry uterus weight and body weight, are demonstrated in Table 1. Body weight was similar between all groups. As expected, dry uterus weight was smaller in OVX animals when compared to control groups, with no difference between $\mathrm{C} 57$ and ApoE animals. As consequence, dry uterus weight/body ratio was also diminished in ovariectomized animals (approximately $84 \%$ ) when compared to sham groups, confirming the efficiency of the OVX procedure.

The effects of endogenous female sex hormones removal on plasma cholesterol levels are displayed in Figure 1. As expected, ApoE mice present hypercholesterolemia (Sham: $345 \pm 14 \mathrm{mg} / \mathrm{dL}, \mathrm{p}<0.01$ ) when compared to C57 animals (Sham: $52 \pm 4 \mathrm{mg} / \mathrm{dL}$ ). Ovariectomy did not modify plasma cholesterol levels in the C57 OVX group $(64 \pm 2 \mathrm{mg} / \mathrm{dL})$, however it intensified hypercholesterolemia in the ApoE OVX group $(645 \pm 38 \mathrm{mg} / \mathrm{dL}, \mathrm{p}<0.01)$. These data indicate that endogenous female sex hormones can have a protective role against hypercholesterolemia.

Renal function was determined using creatinine clearance, plasma values of urea and urine protein excretion in all studied groups; these results are demonstrated in Figure 2. Hypercholesterolemia did not cause any significant changes in the glomerular filtration rate of female

Table 1 Body weight, dry uterus weight and uterus atrophy index in all studied groups

\begin{tabular}{lcccc}
\hline Parameters & \multicolumn{3}{c}{ Groups } \\
\cline { 2 - 5 } & C57 Sham (8) & C57 OVX (5) & ApoE Sham (10) & ApoE OVX (6) \\
\hline Body weight $(\mathrm{g})$ & $21.8 \pm 0.7$ & $21.9 \pm 0.7$ & $22.0 \pm 0.9$ & $22.2 \pm 0.9$ \\
Uterus weight $(\mathrm{mg})$ & $13.5 \pm 1.6$ & $2.1 \pm 0.1^{*}$ & $15.4 \pm 1.1$ & $2.5 \pm 0.5^{*}$ \\
Uterus atrophy index $(\mathrm{mg} / \mathrm{g})$ & $0.62 \pm 0.07$ & $0.10 \pm 0.01^{*}$ & $0.7 \pm 0.01$ & $0.11 \pm 0.02^{*}$ \\
\hline
\end{tabular}

All values are expressed as means \pm SEMs. The number in parentheses represents the number of animals in each group. ${ }^{*} p<0.05$ vs. sham animals. 


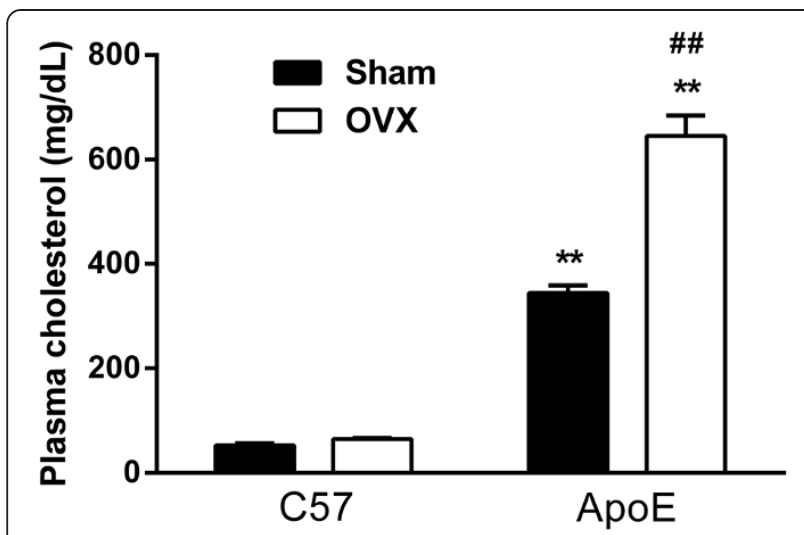

Figure 1 Evaluation of the effects of endogenous female sex hormones removal on total plasma cholesterol levels. As expected, ApoE mice present hypercholesterolemia, which was further increased after ovariectomy. C57 Sham $n=7$, C57 OVX $n=6$, ApoE Sham $n=7$, ApoE OVX $n=9$. Values are means \pm SEMs. ${ }^{* *} p<0.01$ vs. C57; ${ }^{* \#} p<0.01$ vs. respective control. Two-way ANOVA followed by Tukey's post hoc test.

ApoE mice (C57 Sham: $171 \pm 17$; ApoE Sham: $140 \pm$ $26 \mu \mathrm{L} / \mathrm{min})$. The removal of endogenous female sex hormones resulted in decreased creatinine clearance in both C57 OVX $(112 \pm 8 \mu \mathrm{L} / \mathrm{min}, \mathrm{p}<0.05)$ and ApoE OVX $(61 \pm 10 \mu \mathrm{L} / \mathrm{min}, \mathrm{p}<0.01)$ groups; nevertheless, this reduction was greater in the ApoE OVX group (approximately 56\%). Plasma values of urea (Figure 2B) were increased in ApoE animals (Sham: $73 \pm 7$; OVX: $73 \pm$ $8 \mathrm{mg} / \mathrm{dL}, \mathrm{p}<0.05$ ) when compared to C57 group (Sham: $49 \pm 3 \mathrm{mg} / \mathrm{dL}$ ). However, ovariectomy did not modify uremia in either C57 OVX $(60 \pm 4 \mathrm{mg} / \mathrm{dL})$ or ApoE OVX when compared to their respective controls. Evaluation of the 24-hour urine protein excretion (Figure 2B) revealed that neither hypercholesterolemia (ApoE Sham: $26.4 \pm 3.5 \mathrm{mg} / 24 \mathrm{~h}$ ) nor ovariectomy (C57 OVX: $33.7 \pm$ $4.7 \mathrm{mg} / 24 \mathrm{~h}$ ) resulted in altered proteinuria when compared to C57 Sham $(25.1 \pm 5.7 \mathrm{mg} / 24 \mathrm{~h})$. However, when these two situations were concomitant, 24-hour urine protein excretion is augmented (ApoE OVX: $49.6 \pm$ $5.8 \mathrm{mg} / 24 \mathrm{~h}, \mathrm{p}<0.01)$. Taken together, these data indicate that endogenous female sex hormones can delay hypercholesterolemia-induced renal dysfunction.

The histological evaluation for glomerular superoxide anion production (DHE fluorescence - A) and glomerular lipid deposition (Oil-Red-O staining - B) were performed in C57 and ApoE mice (Figure 3). As expected, ApoE animals presented increased oxidative stress into the glomerulus (ApoE Sham: $13.0 \pm 0.7 \mathrm{au}, \mathrm{p}<0.05$ ) when compared to the C57 group (C57 Sham: $9.2 \pm 0.4 \mathrm{au}$ ). The removal of endogenous female sex hormones resulted in augmented superoxide anion production in both C57 (C57 OVX: $22.8 \pm 1.0 \mathrm{au})$ and ApoE $(34.0 \pm 1.4 \mathrm{au})$ mice (Figure 3A). The quantification of glomerular Oil-Red-O

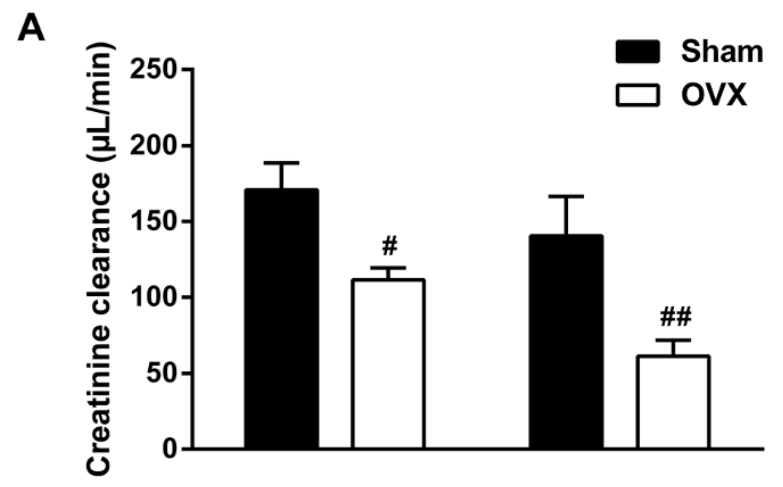

B

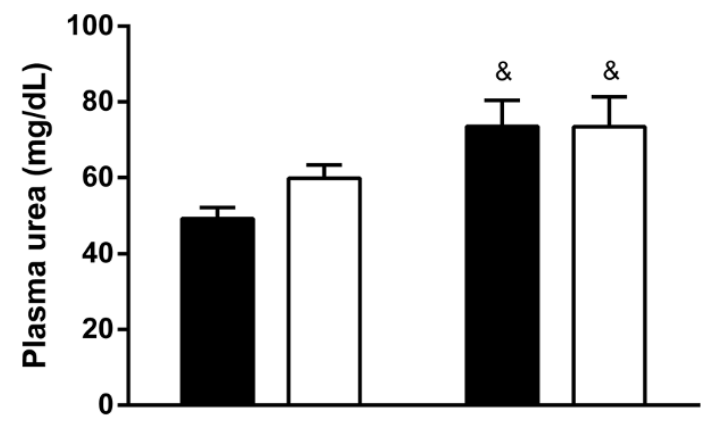

C

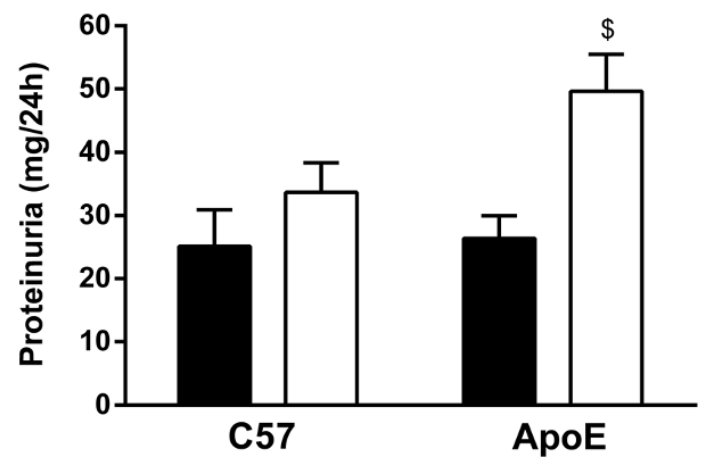

Figure 2 Renal function evaluation using creatinine clearance (A) plasma levels of urea (B) and proteinuria (C). The association of hypercholesterolemia and ovariectomy resulted in a marked renal dysfunction, as demonstrated by the reduced glomerular filtration rate and increased uremia and proteinuria. C57 Sham $n=10-12$, C57 OVX $n=8-11$, ApoE Sham $n=7-13$, ApoE OVX $n=7-12$. Values are means \pm SEMs. ${ }^{\#} p<0.05$ and ${ }^{\# \#} p<0.01$ vs. respective control; $\& p<0.05$ vs. C57 sham; ${ }^{\$} p<0.05$ vs. all other groups. Two-way ANOVA followed by Tukey's post hoc test.

staining (Figure 3B) demonstrated no lipid deposition in either C57 Sham $(0 \pm 0 \%)$ or C57 OVX $(0 \pm 0 \%)$. ApoE mice exhibited increased glomerular lipid deposition (ApoE Sham: $0.07 \pm 0.01 \%$ ), which was not exacerbated by ovariectomy (ApoE OVX: $0.052 \pm 0.01 \%$ ).

ER- $\alpha$ protein expression was evaluated in both the renal cortex and medulla from $\mathrm{C} 57$ and ApoE mice via Western blot analysis (Figure 4). Immunoblotting of the 


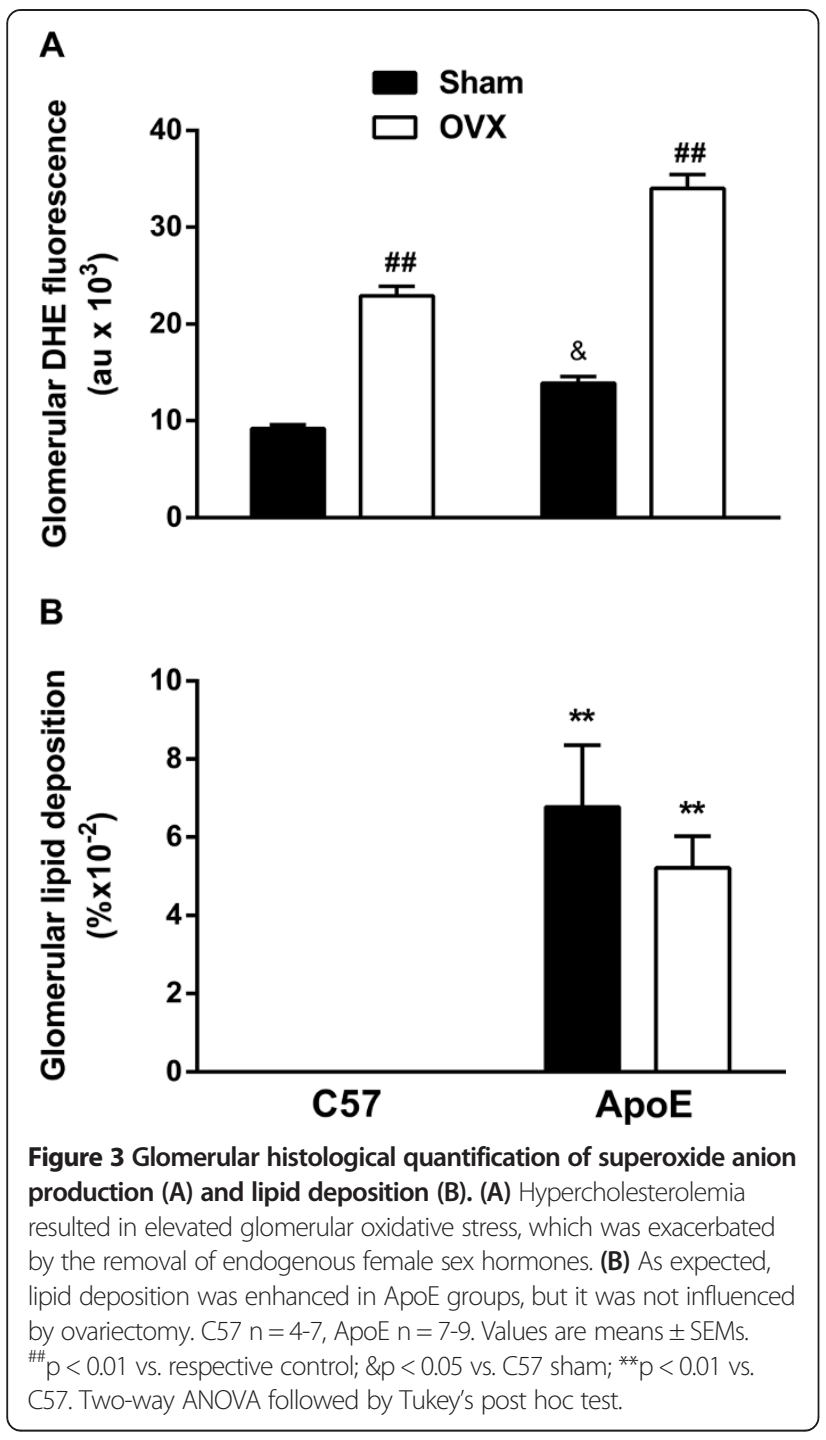

renal cortex (A) demonstrated that ER $\alpha$ protein expression was reduced by ovariectomy in C57 (OVX: $0.78 \pm$ $0.05 \mathrm{au}$ ) and ApoE (OVX: $0.81 \pm 0.04 \mathrm{au}$ ) animals when compared to their respective controls (C57 Sham: $1.00 \pm$ 0.04; ApoE Sham: $1.04 \pm 0.03 \mathrm{au}$ ). Medullary ER $\alpha$ protein expression (B) was affected by neither hypercholesterolemia nor ovariectomy (C57 Sham: 1.00 $\pm 0.04 ;$ C57 OVX: $1.03 \pm 0.02$; ApoE Sham: $0.95 \pm 0.06$; ApoE OVX: $1.00 \pm 0.03 \mathrm{au})$.

\section{Discussion}

In the present study, we evaluated the effects of endogenous female sex hormones on the renal function of hypercholesterolemic mice. Our data demonstrates that the removal of the ovaries from ApoE mice lead to remarkable renal dysfunction, indicating that endogenous female sex hormones can play a protective role against hypercholesterolemia-induced kidney injury.

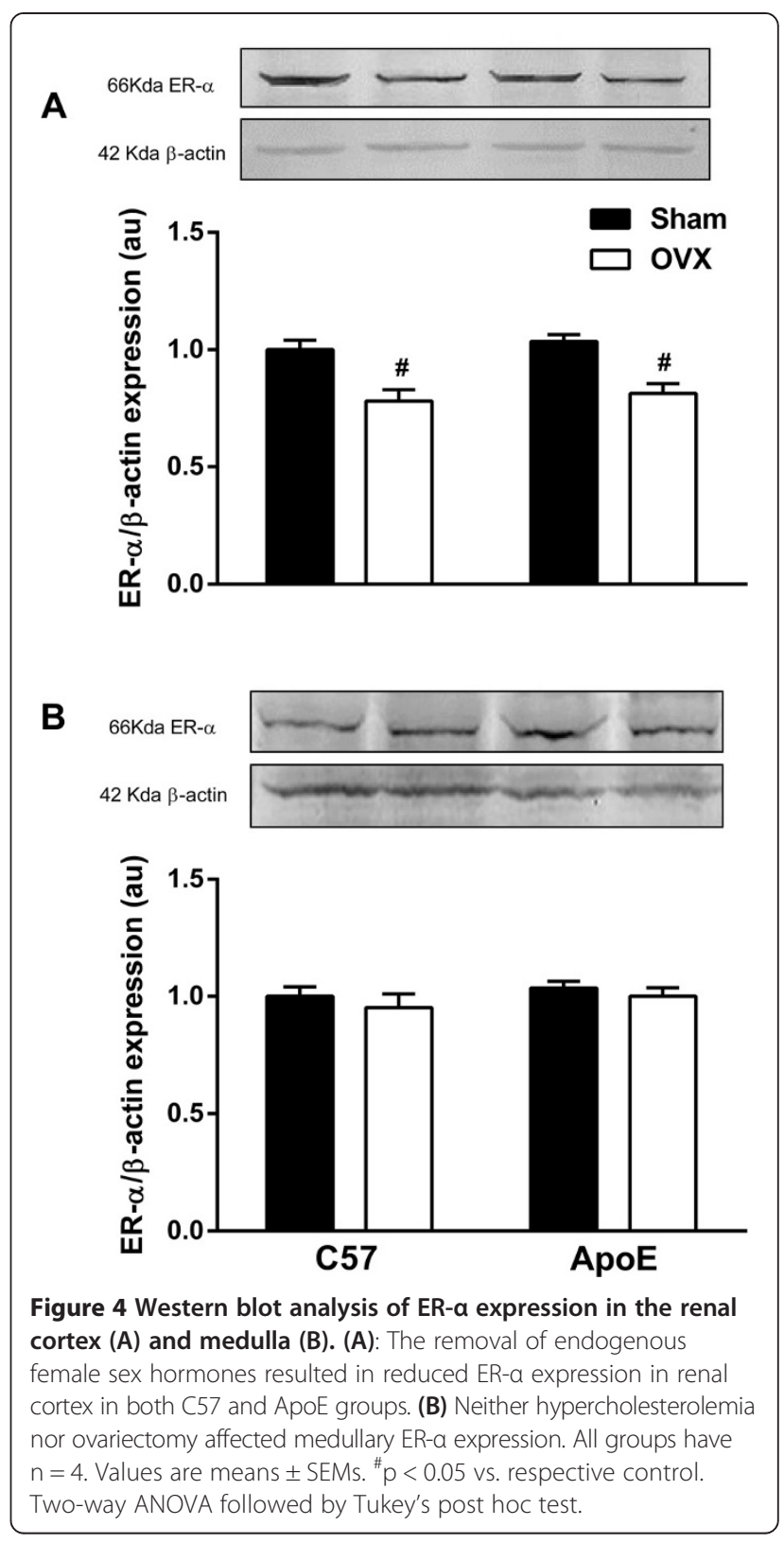

Female endogenous sex hormones, especially the steroid hormone $17 \beta$-estradiol plays critical roles in the reproductive tract, mammary gland, brain, skeletal and cardiovascular systems $[19,20]$. In the reproductive tract, the role of estrogen in uterine epithelial cell division and cell death has been extensively studied, and the results demonstrate that estrogen induces cell division and prevents cell death in this tissue [21]. As expected, the present investigation revealed that mice underwent ovariectomy exhibited remarkable uterine atrophy when compared to control animals, with no differences between C57 and ApoE mice. Previous studies from our laboratory also demonstrated that the removal of endogenous female hormones results in a 
decreased uterus weight similar to C57 and ApoE mice [22]. Although we did not measure plasma levels of female hormones, the reduction in uterus weight can be considered a good marker of the efficacy of ovariectomy surgery, as previously reported $[22,23]$.

In the present investigation, plasma cholesterol levels were elevated in ApoE mice compared to C57 controls. Ovariectomy did not modify this parameter in C57 animals; however, it exacerbated hypercholesterolemia in the ApoE OVX group. It is well established that estrogens are important modulators of lipid metabolism and that premenopausal women are largely protected from a variety of cardiovascular diseases, including dyslipidemia [24]. High serum estrogen levels are associated with favorable lipid profiles, as evidenced by increased HDLcholesterol and decreased LDL-cholesterol levels [24]. Estrogens induce these alterations through a variety of mechanisms, such as reduction of LDL oxidation [25], changes in LDL receptor expression [26] and decreased hepatic lipase dependent catabolism of HDL particles [27].

Renal function was evaluated using creatinine clearance, plasma levels of urea and daily protein excretion. The removal of endogenous female hormones resulted in a slight reduction in the renal function of $\mathrm{C} 57$ animals; however, this effect was much more prominent in ApoE animals. In contrasting with previous data from our laboratory showing that young male ApoE mice present a marked renal dysfunction [28], the present study indicates that female ApoE mice are protected from renal injury, as they present a normal creatinine clearance. Despite this observation, ApoE mice also have greater levels of uremia and increased renal oxidative stress, indicating that although the glomerular filtration rate was not significantly altered, these animals may already present a reduced renal reserve. As a consequence, when the kidney is challenged by other risk factors, such as the reduction in female sex hormones, the loss of renal function is intensified, as we observed in the ApoE OVX group.

Although several studies have investigated the protective effects of female hormones on the kidney, the underlying mechanisms remain to be elucidated. Estrogens are able to suppress extracellular matrix synthesis in glomerular mesangial cells through MAPK activity modulation [15] and by modulating transforming growth factor $\beta$ protein expression and signaling [29]. Furthermore, estrogens reduce tubulointersticial fibrosis through increased matrix metalloproteinase activity [16], which limits the progression of glomerulosclerosis. In addition, estrogens can also contribute to podocyte actin stabilization and protect podocytes against oxidant-induced injury, as demonstrated by Catanuto et al. [30,31]. Taken together, these data indicate that female sex hormones can play a protective role in the development and progression of glomerulosclerosis, and consequently prevent or delay the loss of renal function.
Another important effect of estrogen relies on renal nitric oxide (NO) synthesis and/or bioavailability. The NO system consists of three distinct NO synthase (NOS) isoforms, encoded by three distinct genes, including neuronal (nNOS or NOS-1), inducible (iNOS or NOS-2) and endothelial (eNOS or NOS-3) [32]. All of the NO isoforms have been identified in the kidney [33]. NO plays numerous physiological roles in the kidney, including control of renal and glomerular hemodynamics, through interference at multiple physiologically critical steps of nephron function [34]. Estrogens may upregulate eNOS mRNA in renal medullary cells, increase NOS activity and upregulate eNOS protein levels [17]. Corroborating these data, Pérez-Torres [35] demonstrated that in ovariectomized female rats with metabolic syndrome, eNOS expression was significantly lower than in intact animals, indicating that female sex hormones can modulate the renal synthesis of NO. However, changes in NOS expression do not always correlate with NO bioavailability, superoxide anions react extremely rapidly with NO, generating peroxynitrite. Under physiological conditions, this interaction is minimized by endogenous antioxidant defenses, such as superoxide dismutase activity [36]. Nevertheless, during conditions of increased oxidative stress, such as hypercholesterolemia [37], these defenses may not be able to compensate and protect the cells against reactive oxygen species (ROS)-induced damage. In our study, ApoE mice present higher levels of DHE fluorescence in the glomerulus, indicating an increased superoxide anion generation. However, in both ovariectomized groups, especially in ApoE OVX animals, glomerular oxidative stress was further augmented, indicating a protective role for endogenous female sex hormones on ROS generation. Corroborating our data, Borras et al. [18] reported that females have greater concentrations of antioxidant enzymes, resulting in lower production of ROS and that ovariectomy increases ROS generation. Strehlow et al. [38] reported that $17-\beta$ estradiol upregulates $\mathrm{MnSOD}$ and extracellular SOD expression and activity. Therefore, it seems that increased oxidative stress may be a potential mechanism by which the removal of endogenous female sex hormones resulted in renal dysfunction in ApoE mice.

Because ApoE OVX animals presented greater levels of plasma cholesterol than their respective controls, we sought to investigate if the observed increase in hypercholesterolemia contributed to the loss of renal function due to augmented lipid deposition in the kidney. However, we observed similar lipid deposition in both ApoE groups, indicating that this alteration is not likely to be involved in the exacerbated renal dysfunction found in ApoE ovariectomized animals. In contrast with our data, several studies have demonstrated a beneficial effect of estrogen on the formation of atherosclerotic 
lesions, including inhibition of the production and activity of growth factors [39], reduced inflammation [40], improvement of endothelial function [41], and an ameliorated lipid profile [42]. However, the majority of studies suggest that the protective effects of estrogen in animal models of atherosclerosis are mediated by ER- $\alpha$ [43]. In our study, the protein expression of ER- $\alpha$ was diminished in the renal cortex, which might have contributed to similar levels of glomerular lipid deposition in both ovariectomized and sham ApoE animals.

We also investigated the effects of hypercholesterolemia and endogenous female sex hormones removal on estrogen receptor (ER) expression. Under physiological conditions, the biological effects of estrogen depend not only the level of estrogen but also on the distribution and expression levels of the corresponding ERs, ER- $\alpha$ and ER- $\beta$ in the target cell [43]. The kidney contains many ERs and numerous estrogen-regulated genes, which are primarily regulated by ER- $\alpha$ [44]. In our study, both OVX groups presented a reduced ER- $\alpha$ protein expression in the renal cortex, with no alterations in the renal medulla. In accordance with our data, Esqueda et al. [45] also demonstrated a diminished ER- $\alpha$ expression in the renal cortex following ovariectomy in Dahl salt-sensitive rats. This effect is also observed in other tissues, such as the uterus and vagina [43]. Interestingly, in other models of renal injury, such as diabetic nephropathy, there is an association between decreased circulating estrogen levels and reduced renal ER protein expression [46,47]. We propose that the decrease in ER- $\alpha$ expression in mice after ovariectomy contributes to the development of renal damage, especially in the ApoE OVX group.

Although the most prominent effects of ovariectomy are attributed to the lack of estrogen, we cannot rule out the consequences of progesterone deficiency. In general, endogenous progesterone augments the beneficial effects of estrogen [48]. Progesterone can increase endotheliumdependent relaxation [49] and inhibit mitogen-induced growth and proliferation of mesangial cells [50]. Additionally, progesterone can modulate renal function through changes in sympathetic nervous system, decreased cathecholamine secretion by the adrenal medulla [51] and reduced gamma-amminobutyric acid inhibitory effects on rostral ventrolateral medulla [52]. However, more studies are necessary to elucidate the effects of progesterone on the kidney in both normal and pathophysiological situations.

\section{Conclusion}

Endogenous female sex hormones removal led to renal dysfunction, which was remarkably increased in ApoE animals. The mechanisms involved in this renal injury may include augmented oxidative stress and reduced
ER $\alpha$ expression. This investigation highlights the significance of endogenous female sex in maintaining renal homeostasis, especially when associated with other risk factors, such as hypercholesterolemia and emphasizes the importance of plasma cholesterol control in postmenopausal women.

\section{Methods}

\section{Animals and experimental protocol}

The experiments were performed using female C57BL/6 (C57) and ApoE knockout mice (ApoE). The apoE gene was inactivated by homologous recombination in mouse embryonic stem cells, usually in a C57 genetic background. The animals were obtained from the animal facilities of the Health Sciences Center at the Federal University of Espirito Santo, housed according to institutional guidelines for animal research and fed a normal diet. The procedures were previously approved by the institutional Ethics Committee for Use of Animals from the Research Center of Emescam College of Health Sciences (CEUA-EMESCAM, protocol \#006/2010) and were conducted in accordance with the international guidelines for care and use of laboratory animals. All surgery was performed under sodium ketamine + xylazine anesthesia (91.0/9.1 $\mathrm{mg} / \mathrm{kg}$, i.p.), and all efforts were made to minimize suffering.

At 4 weeks of age, C57 and ApoE mice underwent ovariectomy or sham surgery as previously described [53]. Briefly, after an abdominal incision, the ovaries were clamped and removed, and the skin was then sutured before the animals were returned to their cages. The efficacy of the ovariectomy was confirmed two months after surgery, using uterus weight/body weight ratio and by the evaluation of the estrous cycle. As previously described [54], in wild-type mouse the major population of cells in proestrous are nucleated cells; estrous, cornified; metaestrous, leukocytes; diestrous leukocytes. The animals were considered ovariectomized when the microscopic evaluation of vaginal smears showed lack of cells or very few cornified cells. Sham animals were used to experiments during estrous phase of cycle.

After the vaginal smears evaluation, the animals were housed individually in metabolic cages to allow 24-hour urine volume determination and urine collection. Then, the animals were euthanized with an overdose of thiopental (Cristalia, Sao Paulo, Brazil, $200 \mathrm{mg} / \mathrm{kg}$, i.p.) and blood was collected for creatinine, cholesterol and urea measurements. Tissues were perfused with cold phosphatebuffered saline (PBS, pH 7.4, 0.1 M) through the left ventricle and one kidney was removed for Western blot analysis. The remaining kidney was fixed in paraformaldehyde $4 \%$ in PBS for histological evaluation. The uterus was also removed, dried at $37^{\circ} \mathrm{C}$ for 24 hours and 
weighed to confirm the effectiveness of ovariectomy surgery. Serum cholesterol, urea, creatinine and urine creatinine were measured using colorimetric kits (Bioclin ${ }^{\circledR}$, Belo Horizonte, Brazil). Proteinuria was determined in the urine samples by the Bradford method [55]. Creatinine clearance was calculated using plasma and urine creatinine concentrations and urine flow using the standardized formula.

\section{Renal histological analysis}

After perfusion, the kidneys were embedded in OCT compound (Tissue-Tek; Sakura Finetek USA, Torrance, $\mathrm{CA}, \mathrm{USA})$ and stored at $-80^{\circ} \mathrm{C}$ until further use. Eight $\mu \mathrm{m}$ cryosections (Leica, CM 1850, Leica, Wetzlar, Germany) were prepared and mounted on a parallel series of gelatin coated slides and stained with Oil-Red-O (Sigma- Aldrich) to detect neutral lipids or labeled with the fluorescent dye dihydroethidium $(2 \mu \mathrm{M})$ to observe reactive oxygen species formation as previously described [56]. To verify lipid deposition, the images were captured with a color video camera (VKC150; Hitachi, Tokyo, Japan) connected to a microscope (AX70; Olympus, Center Valley, PA) and analyzed with Image $\mathrm{J}$ software (National Institute of Health). To determine oxidative stress, the tissue sections were imaged using a fluorescence microscope (Nikon Ti-S) with a G-2E/C Nikon filter that provided excitation at $530 \mathrm{~nm}$ and emission at $610 \mathrm{~nm}$. All quantifications were performed by a single blind subject.

\section{Protein extraction and Western blotting}

The renal cortex and medulla were dissected using a Sttadie-Rigg microtome and used as separate tissue pools; respective tissues were homogenized as previously described [57]. Proteins were solubilized by heating at $100^{\circ} \mathrm{C}$ for $1 \mathrm{~min}$ in sample buffer $(62.5 \mathrm{mM}$ Tris- $\mathrm{HCl}$, $\mathrm{pH} 6.8,2 \%$ sodium dodecyl sulfate (SDS), 5\% glycerol, $0.01 \%$ bromophenol blue, and $1.7 \% \beta$-mercaptoethanol). Standard SDS-polyacrylamide gel electrophoresis (PAGE) was carried out by loading equal quantities of protein per lane $(100 \mu \mathrm{g})$ into a $10 \%$ SDS-polyacrylamide gel. Proteins were transferred onto nitrocellulose membranes (BioRad, Hercules, CA) in Tris-glycine transfer buffer and incubated with a rabbit polyclonal antibody raised against the C-terminus of estrogen receptor alpha (ER- $\alpha, 1: 500$ in 3\% nonfat dried milk in TBST, overnight, at $4^{\circ} \mathrm{C}$, Santa Cruz, INC) or rabbit polyclonal antibody raised against the C-terminus of $\beta$ actin (1:1000 in 3\% nonfat dried milk in TBST, overnight, at $4^{\circ} \mathrm{C}$, Santa Cruz, INC). Goat antirabbit IgG conjugated with alkaline phosphatase (Sigma Immuno-Chemicals) was used as a secondary antibody (ER- $\alpha$ : 1:1000; $\beta$-actin: 1:4000, respectively). The blots for ER- $\alpha$ and $\beta$-actin (used as an internal control) were visualized by a color development reaction using nitroblue tetrazolium chloride (NBT) and $50 \mathrm{mg} / \mathrm{mL}$ of 5 -bromo- 4-chloro-3-indolylphosphate p-toluidine salt (BCIP) (all from Life Technologies, Rockville, MD) for $5 \mathrm{~min}$. The $\mathrm{ER} \alpha$ and $\beta$ actin bands were analyzed by densitometry using Image J software. Relative expression was normalized by dividing the ER- $\alpha$ values by the corresponding internal control values ( $\beta$-actin).

\section{Statistical analyses}

All data are expressed as the mean \pm SEM. Statistical analysis was performed using two-way ANOVA, followed by Tukey's post hoc test. The level of significance was set at $\mathrm{p}<0.05$.

\section{Competing interests}

The authors declare that they have no competing interests.

\section{Authors' contributions}

SSC: performed experiments; RZC: performed experiments; FPSF: performed experiments, analysed data, interpreted results of experiments; PLP: performed experiments; CMB: analysed data, interpreted results of experiments, edited and revised manuscript; JBG: analysed data, interpreted results of experiments, edited and revised manuscript, approved final version of manuscript; SSM: analysed data, interpreted results of experiments, edited and revised manuscript; ELC: analysed data, interpreted results of experiments, edited and revised manuscript; ALG: conception and design of research, analysed data, interpreted results of experiments, prepared figures, drafted manuscript, edited and revised manuscript, approved final version of manuscript. All authors read and approved the final manuscript.

\section{Acknowledgements}

JBG is supported by the State Agency for the Development of Science and Technology (002/2009 - 45446121 Grant. SSM is supported by the National Council for the Development of Science and Technology (305188/2012-7 Grant) and the State Agency for the Development of Science and Technology (012/2009-48473677 Grant). ECV is supported by the National Council for the Development of Science and Technology (302582/2011-8 and 476525/2012-8 Grants) and the State Agency for the Development of Science and Technology (012/2011 - 54498465 Grant). ALG is supported by the National Council for the Development of Science and Technology (473177/2013-7 Grant) and the State Agency for the Development of Science and Technology (012/2011 - 54674166 Grant). The funders had no role in study design, data collection and analysis, decision to publish, or preparation of the manuscript.

\section{Author details}

${ }^{1}$ Laboratory of Translational Physiology, Physiological Sciences Graduate Program, Health Sciences Center, Federal University of Espirito Santo, Av Marechal Campos 1468, 29042-755 Vitoria, ES, Brazil. ${ }^{2}$ Morphology Department, Health Sciences Center, Federal University of Espirito Santo, Vitoria, ES, Brazil. ${ }^{3}$ Department of Physiology and Pathology, Health Sciences Center, Federal University of Paraiba, Joao Pessoa, PB, Brazil. ${ }^{4}$ Division of Pediatric Endocrinology, John Hopkins University, School of Medicine, $600 \mathrm{~N}$. Wolfe Street/Room 4-106, Baltimore, MD 21287, USA. ${ }^{5}$ Pharmaceutical Sciences Graduate Program, University of Vila Velha, Vila Velha, ES, Brazil. ${ }^{6}$ Laboratory of Cellular Toxicology, Physiological Sciences Graduate Program, Health Sciences Center, Federal University of Espirito Santo, Av Marechal Campos 1468, 29042-755 Vitoria, ES, Brazil.

Received: 3 September 2014 Accepted: 15 November 2014 Published: 25 November 2014

\section{References}

1. Arsenault BJ, Kritikou EA, Tardif J: Regression of atherosclerosis. Curr Cardiol Rep 2012, 14:443-449.

2. Wang JC, Bennett M, Aging and atherosclerosis: Mechanisms, functional consequences and potential therapeutics for cellular senescence. Circ Res 2012, 111:245-259.

3. Ruilope $L M$, Bakris GL: Renal function and target organ damage in hypertension. Eur Heart J 2011, 32:1599-1604. 
4. Plump AS, Smith JD, Hayek T, Aalto-Setälä K, Walsh A, Verstuyft JG, Rubin EM, Breslow JL: Severe hypercholesterolemia and atherosclerosis in apolipoprotein E-deficient mice created by homologous recombination in ES cells. Cell 1992, 71:343-53

5. Piedrahita JA, Zhang SH, Hagaman JR, Oliver PM, Maeda N: Generation of mice carrying a mutant apolipoprotein $\mathrm{E}$ gene inactivated by gene targeting in embryonic stem cells. Proc Natl Acad Sci USA 1992, 89:4471-5.

6. Vasquez EC, Peotta VA, Gava AL, Pereira TM, Meyrelles SS: Cardiac and vascular phenotypes in the apolipoprotein E-deficient mouse. J Biomed Sci 2012, 13:19-22.

7. Li X, Liu Y, Zhang H, Ren L, Li Q, Li N: Animal models for atherosclerosis research: a review. Protein Cell 2011, 2:189-201.

8. Jawien J, Nastalek P, Korbut R: Mouse models of experimental atherosclerosis. J Physiol Pharmacol 2004, 55:503-517.

9. Muntner P, Coresh J, Smith JC, Eckfeldt J, Klag MJ: Plasma lipids and risk of developing renal dysfunction: the atherosclerosis risk in communities study. Kidney Int 2000, 58:293-301.

10. Schaeffner ES, Kurth T, Curhan GC, Glynn RJ, Rexrode KM, Baigent C, Curing JE, Gaziano JM: Cholesterol and the risk of renal dysfunction in apparently healthy men. J Am Soc Nephrol 2003, 14:2084-2091.

11. Magoori K, Kang MJ, Ito MR, Kakuuchi H, loka RX, Kamataki A, Kim DH, Asaba H, Iwasaki S, Takei YA, Sasaki M, Okazaki M, Takahashi S, Ono M, Nose M, Sakai J, Fujino T, Yamamoto TT: Severe hypercholesterolemia, impaired fat tolerance, and advanced atherosclerosis in mice lacking both low density lipoprotein receptor related protein 5 and apolipoprotein $\mathrm{E}$. J Biol Chem 2003, 278:11331-11336.

12. Pérez-López FR, Larrad-Mur L, Kallen A, Chedraui P, Taylor HS: Gender differences in cardiovascular disease: hormonal and biochemical influences. Reprod Sci 2010, 17:511-531.

13. Eriksen $\mathrm{BO}$, Ingebretsen OC: The progression of chronic kidney disease: a 10-year population-based study of the effects of gender and age. Kidney Int 2006, 69:375-382.

14. Evans M, Fryzek JP, Elinder CG, Cohen SS, McLaughlin JK, Nyren O, Fored CM: The natural history of chronic renal failure: results from an unselected population-based, inception cohort in Sweden. Am J Kidney Dis 2005, 46:863-870.

15. Krepinsky J, Ingram AJ, James L, Ly H, Thai K, Cattran DC, Miller JA, Scholey JW 17beta-Estradiol modulates mechanical strain-induced MAPK activation in mesangial cells. J Bio/ Chem 2002, 277:9387-9394.

16. Mankhey RW, Wells CC, Bhatti F, Maric C: $17 \beta$-Estradiol supplementation reduces tubulointerstitial fibrosis by increasing MMP activity in the diabetic kidney. Am J Physiol Regul Integr Comp Physiol 2007, 292:R769-R777.

17. Pérez-Torres I, Guarner V, El Hafidi M, Baños G: Sex hormones, metabolic syndrome and kidney. Curr Top Med Chem 2011, 11:1694-1705.

18. Borras C, Sastre J, Garcia-Sala D, Lloret A, Pallardo FV, Vina J: Mitochondria from females exhibit higher antioxidant gene expression and lower oxidative damage than males. Free Radic Biol Med 2003, 34:546-552.

19. Couse JF, Korach KS: Estrogen receptor null mice: what have we learned and where will they lead us? Endocr Rev 1999, 20:358-417.

20. Hall JM, Couse JF, Korach KS: The multifaceted mechanisms of estradiol and estrogen receptor signaling. J Biol Chem 2001, 276:36869-36872.

21. Martin L, Pollard JW, Fagg B: Oestriol, oestradiol-17B and the proliferation and death of uterine cells. J Endocr 1976, 69:103-115.

22. Cola MS, Gava AL, Meyrelles SS, Vasquez EC: Endothelial dysfunction of resistance vessels in female apolipoprotein E-deficient mice. Lipids Health Dis 2010, 9:51.

23. Freudenberger T, Oppermann M, Heim HK, Mayer P, Kojda G, Schrör K, Fischer JW: Proatherogenic effects of estradiol in a model of accelerated atherosclerosis in ovariectomized ApoE-deficient mice. Basic Res Cardiol 2010, 105:479-486

24. Miller VM, Duckles S: Vascular actions of estrogens: functional implications. Pharmacol Rev 2008, 60:210-241.

25. Sugioka K, Shimosegawa $Y$, Nakano M: Estrogens as natural antioxidants of membrane phospholipid peroxidation. FEBS Lett 1987, 210:37-39.

26. Colvin PL Jr: Estrogen increases low-density lipoprotein receptor-independent catabolism of apolipoprotein b in hyperlipidemic rabbits. Metabolism 1996, 45:889-896.

27. Tikkanen MJ, Nikkilä EA, Kuusi T, Sipinen S: High density lipoprotein-2 and hepatic lipase: reciprocal changes produced by estrogen and norgestrel. J Clin Endocrinol Metab 1982, 54:1113-1117.
28. Balarini CM, Oliveira MZ, Pereira TM, Silva NF, Vasquez EC, Meyrelles SS, Gava AL: Hypercholesterolemia promotes early renal dysfunction in apolipoprotein E-deficient mice. Lipids Health Dis 2011, 10:220.

29. Dixon A, Maric C: 17ß-Estradiol attenuates diabetic kidney disease via regulating extracellular matrix and transforming growth factor- $\beta$ protein expression and signaling. Am J Physiol Renal Physiol 2007, 293:F1678-F1690.

30. Catanuto P, Doublier S, Lupia E, Fornoni A, Berho M, Karl M, Striker GE, Xia X, Elliot S: 17-Estradiol and tamoxifen upregulate estrogen receptor a and regulate podocyte signaling pathways in a model of type 2 diabetes. Kidney Int 2009, 75:1194-1201.

31. Catanuto P, Fornoni A, Pereira-Simon S, Wu F, Burnstein KL, Xia X, Conti F, Lenzi A, Elliot S: In vivo $17 \beta$-estradiol treatment contributes to podocyte actin stabilization in female db/db mice. Endocrinology 2012, 153:5888-5895.

32. Tsutsui M, Shimokawa H, Otsuji Y, Ueta Y, Sasaguri Y, Yanagiraha N: Nitric oxide synthases and cardiovascular diseases: insights from genetically modified mice. Circ J 2009, 6:986-993.

33. Mount PF, Power DA: Nitric oxide in the kidney: functions and regulation of synthesis. Acta Physiol (Oxf) 2006, 6:433-446.

34. Dellamea BS, Leitão CB, Friedman R, Canani LH: Nitric oxide system and diabetic nephropathy. Diabetol Metab Syndr 2014, 6:17.

35. Pérez-Torres I, Roque P, El Hafidi M, Baños G: Association of renal damage and oxidative stress in a rat model of metabolic syndrome. Influence of gender. Free Radic Res 2009, 43:761-771.

36. Meyrelles SS, Peotta VA, Pereira TM, Vasquez EC: Endothelial dysfunction in the apolipoprotein E-deficient mouse: insights into the influence of diet, gender and aging. Lipids Health Dis 2011, 10:211.

37. Balarini CM, Leal MA, Gomes IB, Pereira TM, Gava AL, Meyrelles SS, Vasquez EC: Sildenafil restores endothelial function in the apolipoprotein $\mathrm{E}$ knockout mouse. J Trans/ Med 2013, 11:3.

38. Strehlow K, Rotter S, Wassmann S, Adam O, Grohe C, Laufs K, Bohm M, Nickenig $\mathrm{G}$ : Modulation of antioxidant enzyme expression and function by estrogen. Circ Res 2003, 93:170-177.

39. Meyer MR, Haas E, Prossnitz ER, Barton M: Non-genomic regulation of vascular cell function and growth by estrogen. Mol Cell Endocrinol 2009, 308:9-16

40. Nofer JR: Estrogens and atherosclerosis: insights from animal models and cell systems. J Mol Endocrinol 2012, 48:R13-R29.

41. Barton M: Cholesterol and atherosclerosis: modulation by oestrogen. Curr Opin Lipidol 2013, 24:214-220.

42. Knopp RH, Paramsothy P, Retzlaff BM, Fish B, Walden C, Dowdy A, Tsunehara C, Aikawa K, Cheung MC: Sex differences in lipoprotein metabolism and dietary response: basis in hormonal differences and implications for cardiovascular disease. Curr Cardiol Rep 2006, 8:452-459.

43. Xu Y, Ding J, Ma XP, Ma YH, Liu ZQ, Lin N: Treatment with Panax ginseng antagonizes the estrogen decline in ovariectomized mice. Int J Mol Sci 2014, 15:7827-7840.

44. Jelinsky SA, Harris HA, Brown EL, Flanagan K, Zhang X, Tunkey C, Lai K, Lane MV, Simcoe DK, Evans MJ: Global transcription profiling of estrogen activity: estrogen receptor alpha regulates gene expression in the kidney. Endocrinology 2003, 144:701-710.

45. Esqueda ME, Craig T, Hinojosa-Laborde C: Effect of ovariectomy on renal estrogen receptor-alpha and estrogen receptor-beta in young salt-sensitive and -resistant rats. Hypertension 2007, 50:768-772.

46. Wells CC, Riazi S, Mankey RW, Bhatti F, Ecelbarger C, Maric C: Diabetic nephropathy is associated with decreased circulating estradiol levels and imbalance in the expression of renal estrogen receptors. Gend Med 2005, 2:227-237.

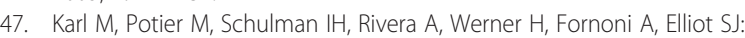
Autocrine activation of the local insulin-like growth factor I system is up-regulated by estrogen receptor (ER)-independent estrogen actions and accounts for decreased ER expression in type 2 diabetic mesangial cells. Endocrinology 2005, 146:889-900.

48. Dubey RK, Oparil S, Imthurn B, Jackson EK: Sex hormones and hypertension. Cardiovasc Res 2002, 53:688-708

49. Miller VM, Vanhoutte PM: Progesterone and modulation of endothelium-dependent responses in canine coronary arteries. Am J Physiol 1991, 261:R1022-1027.

50. Dubey RK, Jaxkson EK, Rupprecht HD, Sterzel RB: Factors controlling growth and matrix production in vascular smooth muscle and glomerular mesangial cells. Curr Opin Nephrol Hypertens 1997, 6:88-105. 
51. Armstrong SM, Stuenkel EL: Progesterone regulation of catecholamine secretion from chromaffin cells. Brain Res 2005, 1043:76-86.

52. Heesch CM, Rogers RC: Effects of pregnancy and progesterone metabolites on regulation of sympathetic outflow. Clin Exp Pharmacol Physiol 1995, 22:136-142.

53. Dantas APV, Scivoletto R, Fortes ZB, Nigro D, Carvalho MHC: Influence of female sex hormones on endothelium-derived vasoconstrictor prostanoid generation in microvessels of spontaneously hypertensive rats. Hypertension 1999, 34:914-919.

54. Fata JE, Chaudhary V, Khokha R: Cellular turnover in the mammary gland is correlated with systemic levels of progesterone and not 17 beta-estradiol during the estrous cycle. Biol Reprod 2001, 56:680-688.

55. Bradford MM: A rapid and sensitive method for the quantitation of microgram quantities of protein utilizing the principle of protein-dye binding. Anal Biochem 1976, 72:248-254.

56. Lima LCF, Porto ML, Campagnaro BP, Tonini CL, Nogueira BV, Pereira TMC Vasquez EC, Meyrelles SS: Mononuclear cell therapy reverts cuff-induced thrombosis in apolipoprotein E-deficient mice. Lipids Health Dis 2012, 11:96

57. Gracelli JB, Souza-Menezes J, Barbosa CM, Ornellas FS, Takiya CM, Alves LM, Wengert M, Feltran Gda S, Caruso-Neves C, Moyses MR, Prota LF, Morales $\mathrm{MM}$ : Role of estrogen and progesterone in the modulation of CNG-A1 and $\mathrm{Na} / \mathrm{K}+-$ ATPase expression in the renal cortex. Cell Physiol Biochem 2012, 30:160-172.

doi:10.1186/1476-511X-13-176

Cite this article as: Carneiro et al.: Endogenous female sex hormones delay the development of renal dysfunction in apolipoprotein E-deficient mice. Lipids in Health and Disease 2014 13:176.

\section{Submit your next manuscript to BioMed Central and take full advantage of:}

- Convenient online submission

- Thorough peer review

- No space constraints or color figure charges

- Immediate publication on acceptance

- Inclusion in PubMed, CAS, Scopus and Google Scholar

- Research which is freely available for redistribution 